\title{
Is cervical disc arthroplasty good for congenital cervical stenosis?
}

\author{
Peng-Yuan Chang, MD, 1,3 Hsuan-Kan Chang, MD, 1,3 Jau-Ching Wu, MD, PhD, 1,3 \\ Wen-Cheng Huang, MD, PhD, , ${ }^{1,3}$ Li-Yu Fay, MD, , ${ }^{1,3}$ Tsung-Hsi Tu, MD, ${ }^{1,3,5}$ Ching-Lan Wu, MD, ${ }^{2,3}$ and \\ Henrich Cheng, MD, PhD ${ }^{1-3}$
}

1'Department of Neurosurgery, Neurological Institute, and ${ }^{2}$ Department of Radiology, Taipei Veterans General Hospital; ${ }^{3}$ School of Medicine, and ${ }^{4}$ Institute of Pharmacology, National Yang-Ming University; and ${ }^{5}$ Molecular Medicine Program, International Graduate Program, Academia Sinica, Taipei, Taiwan

\begin{abstract}
OBJECTIVE Cervical disc arthroplasty (CDA) has been demonstrated to be as safe and effective as anterior cervical discectomy and fusion (ACDF) in the management of 1- and 2-level degenerative disc disease (DDD). However, there has been a lack of data to address the fundamental discrepancy between the two surgeries (CDA vs ACDF), and preservation versus elimination of motion, in the management of cervical myelopathy associated with congenital cervical stenosis (CCS). Although younger patients tend to benefit more from motion preservation, it is uncertain if CCS caused by multilevel DDD can be treated safely with CDA.
\end{abstract}

METHODS Consecutive patients who underwent 3-level anterior cervical discectomy were retrospectively reviewed. Inclusion criteria were age less than 50 years, CCS (Pavlov ratio $\leq 0.82$ ), symptomatic myelopathy correlated with DDD, and stenosis limited to 3 levels of the subaxial cervical (C3-7) spine. Exclusion criteria were ossification of the posterior longitudinal ligament, previous posterior decompression surgery (e.g., laminoplasty or laminectomy), osteoporosis, previous trauma, or other rheumatic diseases that might have caused the cervical myelopathy. All these patients who underwent 3-level discectomy were divided into 2 groups according to the strategies of management: preservation or elimination of motion (the hybrid-CDA group and the ACDF group). The hybrid-CDA group underwent 2-level CDA plus 1-level ACDF, whereas the ACDF group underwent 3-level ACDF. Clinical assessment was measured by the visual analog scales (VAS) for neck and arm pain, Japanese Orthopaedic Association (JOA) scores, and Nurick grades. Radiographic outcomes were measured using dynamic radiographs for evaluation of range of motion (ROM).

RESULTS Thirty-seven patients, with a mean ( \pm SD) age of $44.57 \pm 5.10$ years, were included in the final analysis. There was a male predominance in this series $(78.4 \%, 29$ male patients), and the mean follow-up duration was $2.37 \pm$ 1.60 years. There were 20 patients in the hybrid-CDA group, and 17 in the ACDF group. Both groups demonstrated similar clinical improvement at 2 years' follow-up. These patients with 3-level stenosis experienced significant improvement after either type of surgery (hybrid-CDA and ACDF). There were no significant differences between the 2 groups at each of the follow-up visits postoperatively. The preoperative ROM over the operated subaxial levels was similar between both groups $\left(21.9^{\circ}\right.$ vs $\left.21.67^{\circ} ; p=0.94\right)$. Postoperatively, the hybrid-CDA group had significantly greater $\operatorname{ROM}\left(10.65^{\circ}\right.$ vs $2.19^{\circ}$; $p<0.001$ ) than the ACDF group. Complications, adverse events, and reoperations in both groups were similarly low.

CONCLUSIONS Hybrid-CDA yielded similar clinical improvement to 3-level ACDF in patients with myelopathy caused by CCS. In this relatively young group of patients, hybrid-CDA demonstrated significantly more ROM than 3-level ACDF without adjacent-segment disease (ASD) at 2 years' follow-up. Therefore, hybrid-CDA appears to be an acceptable option in the management of CCS. The strategy of motion preservation yielded similar improvements of cervical myelopathy to motion elimination (i.e., ACDF) in patients with CCS, while the theoretical benefit of reducing ASD required further validation.

https://thejns.org/doi/abs/10.3171/2016.10.SPINE16317

KEY WORDS anterior cervical discectomy and fusion; congenital cervical stenosis; cervical disc arthroplasty; cervical hybrid arthroplasty; cervical myelopathy; cervical spondylotic myelopathy; Pavlov ratio; Torg ratio

ABBREVIATIONS ACDF = anterior cervical discectomy and fusion; ASD = adjacent-segment disease; CCS = congenital cervical stenosis; CDA = cervical disc arthroplasty; $\mathrm{CSM}$ = cervical spondylotic myelopathy; DDD = degenerative disc disease; IDE = Investigational Device Exemption; JOA = Japanese Orthopaedic Association; ROM = range of motion; $\mathrm{SC}=$ spinal canal; $\mathrm{SCI}=$ spinal cord injury; $\mathrm{VAS}$ = visual analog scale; VB = vertebral body.

SUBMITTED March 17, 2016. ACCEPTED October 18, 2016.

INCLUDE WHEN CITING Published online March 10, 2017; DOI: 10.3171/2016.10.SPINE16317. 


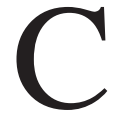

ONGENITAL stenosis of the spine is generally recognized as a developmental insufficiency of the spinal canal (SC) for the nervous elements, most notably in the cervical and lumbar region. Morphologically it can be described as the aberrant development of the pedicle, lamina, or vertebral body (VB). ${ }^{2,3,14,15,18,32}$ The condition presumably puts the spine in a relatively disadvantageous position against the spondylosis, which is supported by the fact that congenital cervical stenosis (CCS) has been established to be a major risk factor for and may predispose to the development of cervical spondylotic myelopathy (CSM). ${ }^{21,25,28,35}$

In the era of CT scans and MRI, various measurements have been advocated to define the presence of CCS in the clinical setting. However, ever since it was first described by Pavlov and Torg, ${ }^{21}$ the ratio of SC to VB (i.e., Pavlov's ratio or Torg's ratio) remains the most gratifying and universally used measurement to define the presence of CCS. This measurement not only has been recognized to have a good correlation with the VB-to-canal ratio on CT and VB-to-CSF column ratio on MRI, but has also been associated with increased risks for CSM, spinal cord injury (SCI), transient neurapraxia, SCI in athletes, and adjacentsegment diseases (ASDs) after anterior cervical discectomy and fusion (ACDF). 2,3,11,17,25,27-31,33,35,36

The application of cervical disc arthroplasty (CDA) in the treatment of cervical degenerative disc diseases (DDDs) has been proven by multiple FDA Investigational Device Exemption (IDE) trials to be a safe and effective alternative to conventional fusion surgery, i.e., ACDF. However, there have been scarce data to specifically address the efficacy and clinical implication of CDA in patients with CCS. Whether these patients can benefit from motion preservation surgery remains elusive. This study aimed to compare the radiographic and clinical outcomes of those patients with CCS who underwent motion preservation surgery (CDA) to those who had conventional fusion surgery (ACDF), and to explore the discrepancies between these two different strategies of reconstruction after cervical discectomy.

\section{Methods}

The study was a retrospective review of radiographic and clinical data that were collected at our institute, Taipei Veterans General Hospital. All consecutive patients who underwent 3 contiguous segments of anterior cervical discectomies from 2008 to 2014 were reviewed. There were 40 patients with CCS but only 37 patients who completed the clinical and radiological follow-up (92.5\%); these 37 were included in the final analysis.

\section{Inclusion and Exclusion Criteria}

Surgical indications in the study included overt myelopathic symptoms and signs, abnormal findings in electrophysiology studies (e.g., motor or somatosensory evoked potentials), as well as substantial compression and resultant stenosis demonstrated by MR images, such as increased intramedullary signal intensities on T2weighted images. The inclusion criteria were patients with symptomatic cervical myelopathy who were 50 years old or younger, and who presented with CCS (defined by a Pavlov ratio $\leq 0.82$ )-related DDD in the cervical spine. All patients responded inadequately to at least 12 weeks of nonsurgical management, including rehabilitation and other medical treatment. Also, the cervical stenoses were limited to 3 levels of the subaxial cervical spine (C3-7).

The exclusion criteria were patients with previous cervical decompression operations (e.g., laminoplasty or laminectomy), ossification of the posterior longitudinal ligament, remarkable cervical trauma, osteoporosis ( T score < $-2.5)$, malignancy, metabolic bone diseases, active infection, inflammatory spondyloarthropathy (e.g., psoriatic arthritis or rheumatic arthritis), or severe systemic diseases (e.g., cirrhosis of the liver).

Only 40 patients met the above inclusionary criteria and the diagnosis of CCS. Thirty-seven patients who had complete follow-up data in the clinics at the $3 \mathrm{rd}, 6 \mathrm{th}, 12 \mathrm{th}$, 18th, and 24th month after surgery and also met the diagnostic criteria of CCS were analyzed. Those who failed to complete at least the 6-month postoperative follow-up were considered lost to follow-up and were excluded from the analysis.

\section{Operative Techniques}

Under general anesthesia, the patient was placed supine, and a right-sided skin incision was made along a horizontal skin crease corresponding to the surgical level. Discectomy was routinely performed with generous decompression of the neural elements, which involved the resection of the posterior longitudinal ligament and resection of the bilateral uncovertebral joints, before the implantation of the prosthesis (i.e., cages or cervical artificial discs). Meticulous care was taken when drilling the endplates, and the proper size of the prosthesis was determined with the assistance of fluoroscopy. During the entire decompression procedure copious irrigation was performed using normal saline. A closed-drain device was routinely used before wound closure. In this series all the fusion segments incorporated a cervical plate, whether it was a 3-level ACDF or a single-level fusion within the hybrid-CDA. In this study all the patients' surgical strategies were decided during a consensus meeting led by the senior authors (H.C. and W.C.H.), and the surgery mainly involved 2 operators (J.C.W. and W.C.H.).

\section{Clinical and Radiographic Evaluations}

Standard plain radiographs, including anterior-posterior, lateral, and dynamic (flexion and extension) views were obtained before the surgery as well as within 3 days postoperatively, and at the 3-, 6-, 12-, 18-, and 24-month follow-up visits to the clinics, and every 12 months thereafter. The segmental range of motion (ROM) was defined by the Cobb angles formed by the uppermost and the most inferior endplates of the operated levels according to the flexion and extension radiographs. The measurements were made by utilizing the quantitative analysis software, SmartIris (Taiwan Electronic Data Processing Co.).

The determination of the Pavlov ratio was obtained from the preoperative lateral plain radiographs while the patient was in the neutral position. The ratio was calcu- 
lated from 2 parameters (Fig. 1): the SC length, which was measured from the middle point of the posterior cortex of the VB to the nearest point of the junction of the corresponding lamina and spinous process, divided by the VB length, which was obtained between the anterior and posterior cortex of the VB. For the fusion levels, any Cobb angular motion $>3^{\circ}$ in the final plain radiographs was considered pseudarthrosis.

Thin-slice CT scans with reconstructed images were performed on every patient who completed more than 12 months of follow-up, and MRI for those who completed 24 months of follow-up.

Clinical results were established by assessment completed at each scheduled clinical visit. Standard preoperative and postoperative questionnaires were handed out; the latter were to be completed at each follow-up time point. The evaluation was conducted with the assistance of 2 specialized nurse assistants by using the visual analog scale (VAS), Japanese Orthopaedic Association (JOA) score, and Nurick grade for myelopathy, under the supervision of physicians. Any ambiguity in clinical judgment was resolved by the neurosurgeon available on site.

\section{Statistical Analysis}

Independent and paired t-tests were applied for the analysis of continuous variables in Excel software (Microsoft, Inc.) A p value $<0.05$ was deemed statistically significant. All values are presented as means \pm standard deviations.

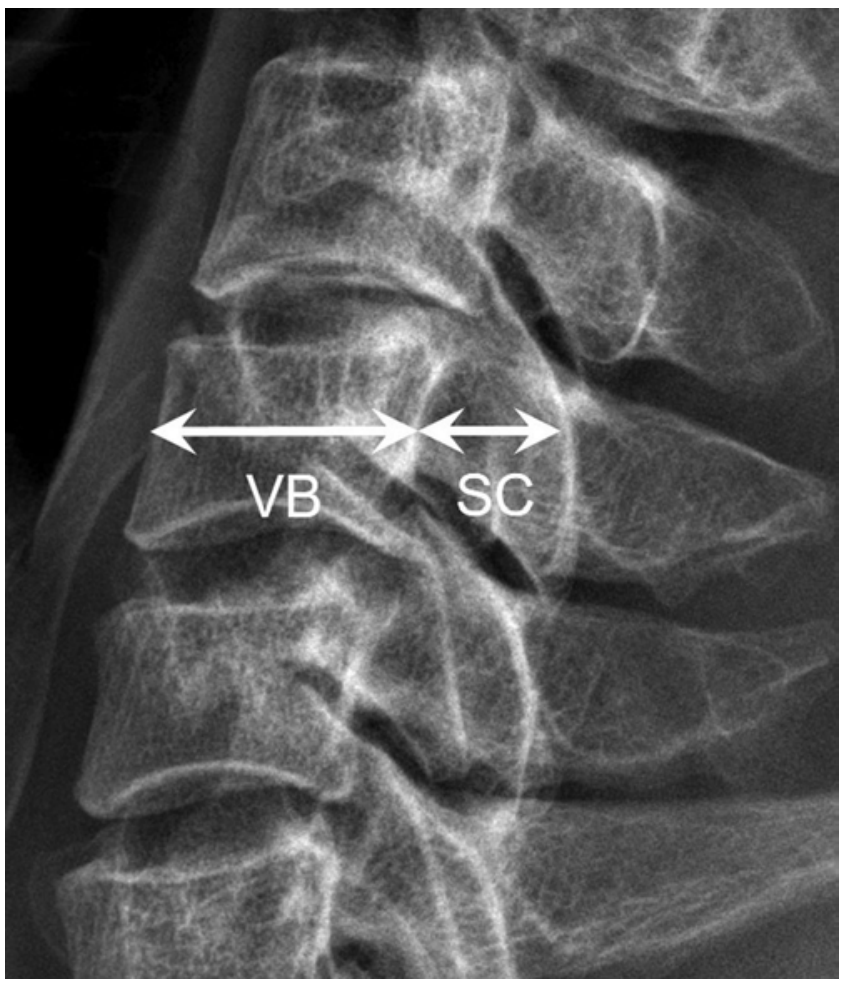

FIG. 1. Measurement of the Pavlov ratio. The ratio was calculated from 2 parameters: SC length, the length from the midpoint of the posterior cortex of the VB to the nearest point at the junction of the lamina and spinous process, divided by VB length, the length between the midpoints of the anterior and posterior cortex of the VB.

\section{Results}

\section{Overall Demographics}

There were a total of 40 patients meeting all of the inclusion criteria (age $\leq 50$ years, 3 -level discectomies, and Pavlov ratio $\leq 0.82$ ). These patients with CCS were analyzed and compared according to the surgery they underwent (i.e., hybrid-CDA, or ACDF). Only 37 patients who completed the clinical and radiological follow-up (92.5\%) were included in this analysis (Table 1). The mean age of these patients was $44.57 \pm 5.10$ years. Male predominance was observed in this study, consisting of 29 male (78.4\%) and 8 female (21.6\%) patients. The average follow-up duration was $2.37 \pm 1.60$ years.

The mean preoperative ROM of the operated levels of the whole patient group was $21.80^{\circ} \pm 9.14^{\circ}$, while the postoperative ROM was $6.89^{\circ} \pm 5.87^{\circ}$. The mean Pavlov ratio was $0.62 \pm 0.10$. In this study, there were 19 patients who underwent discectomies from C-3 to C-6, 17 from C-4 to C-7, and 1 patient had the surgery at C-5 to T-1 (Table 2).

\section{Hybrid-CDA Versus ACDF}

The 37 patients in this analysis were divided into 2 different groups based on the different strategies of reconstruction after the discectomy procedure. The hybridCDA group was composed of 20 patients who underwent motion preservation reconstruction that involved 2 cervical artificial discs and 1 cage (Fig. 2), while the ACDF group had 17 patients who chose to have conventional fusion surgery that required 3 cages (Fig. 3). The decision of reconstruction method was primarily based on the patients' choice after each patient's thorough understanding of the pros and cons of these prostheses.

Demographic statistics were similar between the 2 groups (Table 2). Both demonstrated male predominance: 17 male patients $(85 \%)$ in the hybrid-CDA group and 12 (70.59\%) in the ACDF group. The mean age of the hybrid-CDA group was $44.76 \pm 5.73$ years, and 44.35 \pm 4.40 years for those in the ACDF group $(p=0.81)$. The average follow-up duration of the hybrid-CDA group was $2.60 \pm 1.82$ years, slightly longer than that in the ACDF

TABLE 1. Demographic data

\begin{tabular}{lc}
\hline Characteristics (overall) & Value \\
\hline Sex (\%) & $29(78.4)$ \\
\hline Male & $8(21.6)$ \\
\hline Female & $44.57 \pm 5.10$ \\
\hline Mean age \pm SD (yrs) & $2.37 \pm 1.60$ \\
\hline Mean follow-up \pm SD (yrs) & \\
\hline Operative methods $(\%)$ & $20(54.1)$ \\
\hline Hybrid-CDA & $17(45.9)$ \\
\hline 3-level ACDF & $21.80 \pm 9.14$ \\
\hline Mean preop ROM \pm SD $\left(^{\circ}\right)$ & $6.89 \pm 5.87$ \\
\hline Mean postop ROM \pm SD $\left(^{\circ}\right)^{*}$ & $0.62 \pm 0.10$ \\
\hline Mean SC-VB (Pavlov) ratio \pm SD
\end{tabular}

* This measurement was determined based on radiographs obtained from the patient's last follow-up visit. 
TABLE 2. Group analysis: hybrid-CDA versus ACDF

\begin{tabular}{|c|c|c|c|c|}
\hline \multirow[b]{2}{*}{ Variable } & \multirow[b]{2}{*}{ Overall } & \multicolumn{2}{|c|}{ Group } & \multirow[b]{2}{*}{ p Value* } \\
\hline & & Hybrid-CDA & 3-Level ACDF & \\
\hline No. of patients & 37 & 20 & 17 & \\
\hline Sex & & & & 0.3 \\
\hline Male & 29 & 17 & 12 & \\
\hline Female & 8 & 3 & 5 & \\
\hline Mean age \pm SD (yrs) & $44.57 \pm 5.10$ & $44.76 \pm 5.73$ & $44.35 \pm 4.40$ & 0.81 \\
\hline \multicolumn{5}{|l|}{ Operated levels } \\
\hline C3-6 & 19 & 8 & 11 & \\
\hline C4-7 & 17 & 11 & 6 & \\
\hline $\mathrm{C} 5-\mathrm{T} 1$ & 1 & 1 & 0 & \\
\hline Mean preop $\mathrm{ROM} \pm \mathrm{SD}\left(^{\circ}\right)$ & $21.80 \pm 9.14$ & $21.90 \pm 10.76$ & $21.67 \pm 6.77$ & 0.94 \\
\hline Mean postop $\mathrm{ROM} \pm \mathrm{SD}\left(^{\circ}\right)$ & $6.89 \pm 5.87$ & $10.65 \pm 5.37$ & $2.19 \pm 1.17$ & $<0.001$ \\
\hline Mean SC/VB (Pavlov) ratio \pm SD & $0.62 \pm 0.10$ & $0.60 \pm 0.09$ & $0.64 \pm 0.11$ & 0.18 \\
\hline Mean preop cervical lordosis \pm SD $\left(^{\circ}\right)$ & $6.41 \pm 13.36$ & $8.65 \pm 12.56$ & $4.25 \pm 13.89$ & 0.27 \\
\hline Mean postop cervical lordosis $\pm \operatorname{SD}\left({ }^{\circ}\right)$ & $12.03 \pm 8.84$ & $12.20 \pm 7.14$ & $11.56 \pm 10.46$ & 0.90 \\
\hline \multicolumn{5}{|l|}{ Mean preop clinical scores \pm SD } \\
\hline VAS (neck pain) & $4.23 \pm 2.41$ & $3.89 \pm 2.68$ & $4.75 \pm 1.91$ & 0.34 \\
\hline VAS (arm pain) & $4.24 \pm 2.61$ & $3.75 \pm 2.69$ & $4.92 \pm 2.43$ & 0.22 \\
\hline JOA & $13.13 \pm 2.62$ & $13.06 \pm 3.02$ & $13.23 \pm 2.05$ & 0.86 \\
\hline Nurick & $2.42 \pm 0.84$ & $2.18 \pm 0.87$ & $2.75 \pm 0.71$ & 0.15 \\
\hline \multicolumn{5}{|l|}{ Mean postop 24-mos scores \pm SD } \\
\hline VAS (neck pain) & $2.31 \pm 2.04$ & $1.80 \pm 1.48$ & $2.68 \pm 2.35$ & 0.31 \\
\hline VAS (arm pain) & $1.57 \pm 1.48$ & $1.29 \pm 1.26$ & $1.86 \pm 1.66$ & 0.31 \\
\hline JOA & $15.00 \pm 1.44$ & $14.94 \pm 1.00$ & $15.07 \pm 1.83$ & 0.81 \\
\hline Nurick & $1.24 \pm 0.44$ & $1.25 \pm 0.45$ & $1.23 \pm 0.44$ & 0.91 \\
\hline \multicolumn{5}{|l|}{ Type of CDA } \\
\hline Bryan & & 7 & & \\
\hline Prestige LP & & 11 & & \\
\hline Prodisc-C Nova & & 2 & & \\
\hline \multicolumn{5}{|c|}{ Relative level of fusion segment in hybrid construct } \\
\hline Rostral & & 7 & & \\
\hline Interposing & & 3 & & \\
\hline Caudal & & 10 & & \\
\hline
\end{tabular}

group $(2.10 \pm 1.29$ years). There was no significant difference between the two groups in follow-up duration ( $p$ $=0.35$ ).

Before the operation, both groups presented with similar outcomes in clinical assessment (Fig. 4). The mean VAS score for neck pain was $3.89 \pm 2.68$ in the hybridCDA group and $4.75 \pm 1.91$ in the ACDF group $(p=0.34)$. The VAS score for arm pain also had a similar pattern: $3.75 \pm 2.69$ in the hybrid-CDA group and $4.92 \pm 2.43$ in the ACDF group $(p=0.22)$. The mean JOA scores in the hybrid-CDA group and ACDF group were $13.06 \pm 3.02$ versus $13.23 \pm 2.05(\mathrm{p}=0.86)$, and mean Nurick grades in these groups were $2.18 \pm 0.87$ and $2.75 \pm 0.71$, respectively $(\mathrm{p}=0.15)$. After the surgery, both groups had significant clinical improvement at the 24-month follow-up evaluations (Table 2, Figs. 4 and 5).

Radiographically, both groups presented with a simi- lar Pavlov ratio on preoperative plain radiographs $(0.60 \pm$ 0.09 vs $0.64 \pm 0.11, p=0.18$ ) as well as preoperative $\mathrm{ROM}$ of the operated levels, which was $21.90^{\circ} \pm 10.76^{\circ}$ in the hybrid-CDA group and $21.67^{\circ} \pm 6.77^{\circ}$ in the ACDF group $(\mathrm{p}=0.94)$. With regard to the postoperative ROM, the hybrid-CDA group remarkably gained more ROM in the postoperative follow-up $\left(10.65^{\circ} \pm 5.37^{\circ}\right)$ when compared with that obtained in the ACDF group $\left(2.19^{\circ} \pm 1.17^{\circ}\right)$. The difference in $\mathrm{ROM}$ reached statistical significance with a $\mathrm{p}$ value of 0.0000005 .

In this series, no secondary operation was performed for the purposes of revision, reimplantation of prosthesis due to instrumentation failure, or conversion to fusion surgery for those who underwent CDA. One patient $(5 \%)$ in the hybrid-CDA group developed left-sided C-5 palsy after the operation. Prompt rehabilitation was implemented for the patient, and neurological status of this patient 

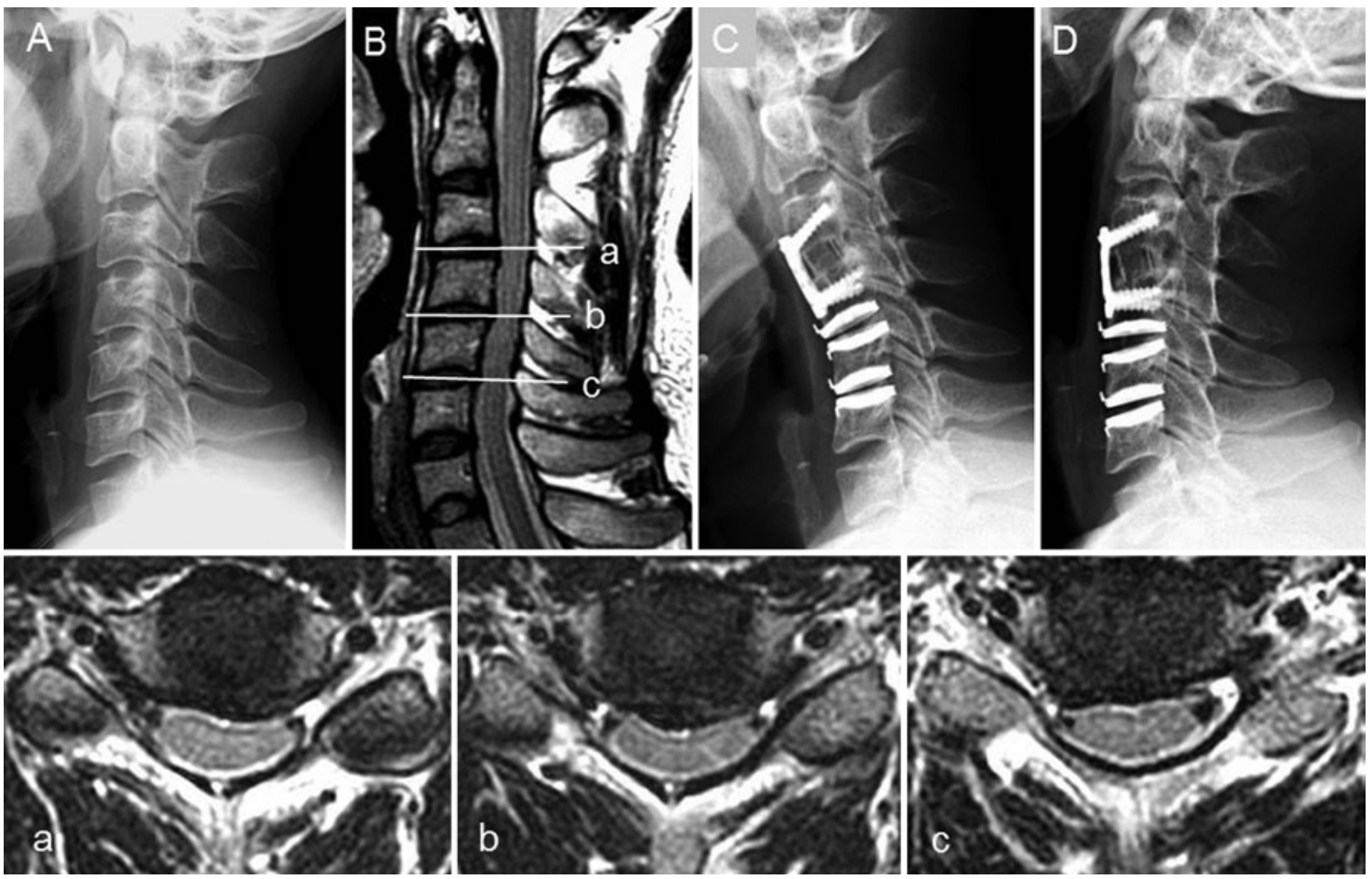

FIG. 2. Illustration of a patient in the hybrid-CDA group. The patient was a 33-year-old man who underwent cervical discectomies at the level of C3-6, followed by fusion at the level of C3-4, and CDA at C4-6. A and B: Preoperative plain radiographs and MRI. C and D: Postoperative plain radiographs showing flexion and extension. a-c: The spinal cord compression is demonstrated by the axial view of each section (shown in B).
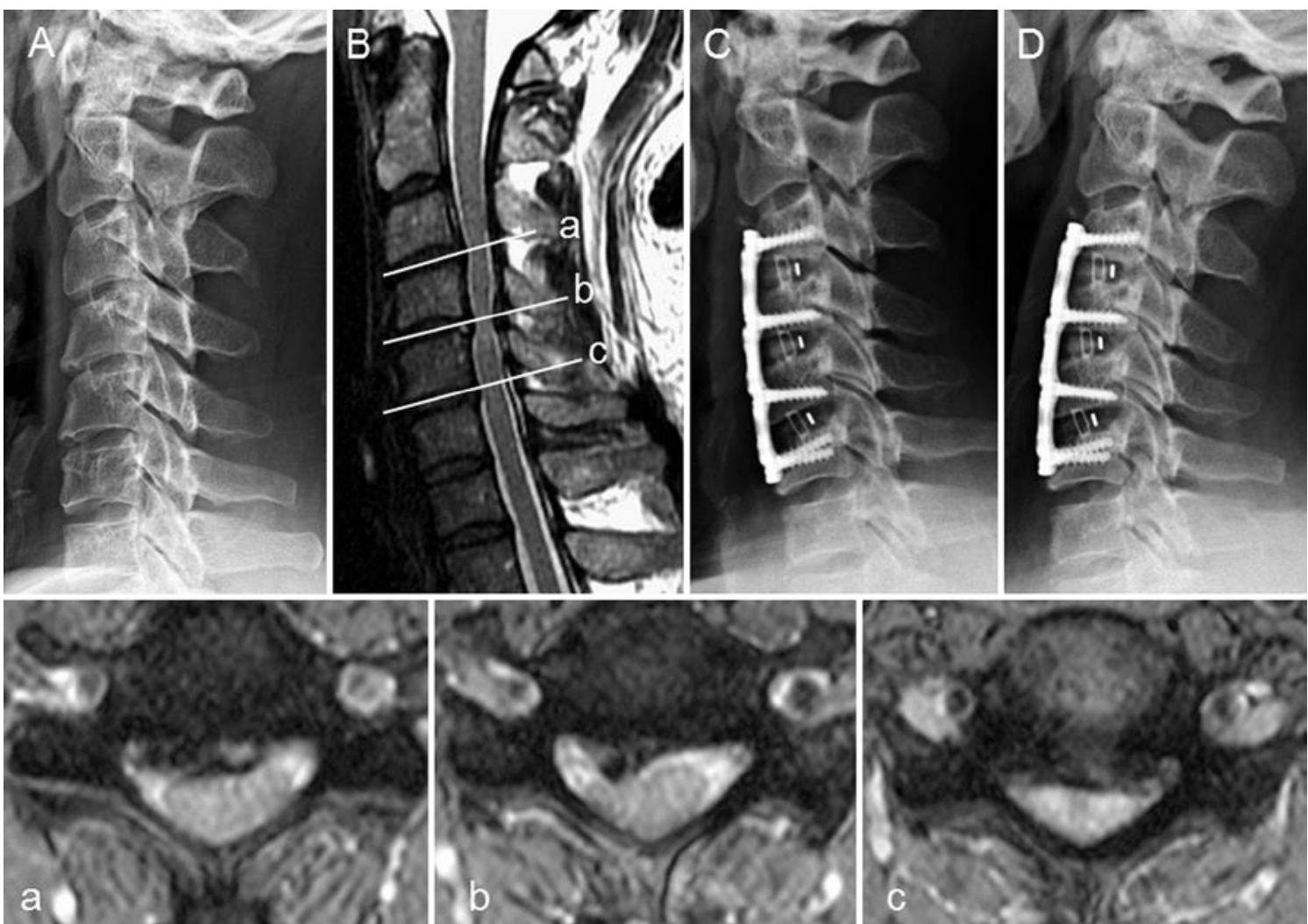

FIG. 3. Illustration of a patient in the ACDF group. The patient was a 47-year-old man who had ACDF at the level of C3-6. A and B: Preoperative plain radiograph and MR image. $C$ and D: Postoperative plain radiographs showing flexion and extension. a-c: The severity of spinal cord compression is shown in the axial views (demonstrated in B). 

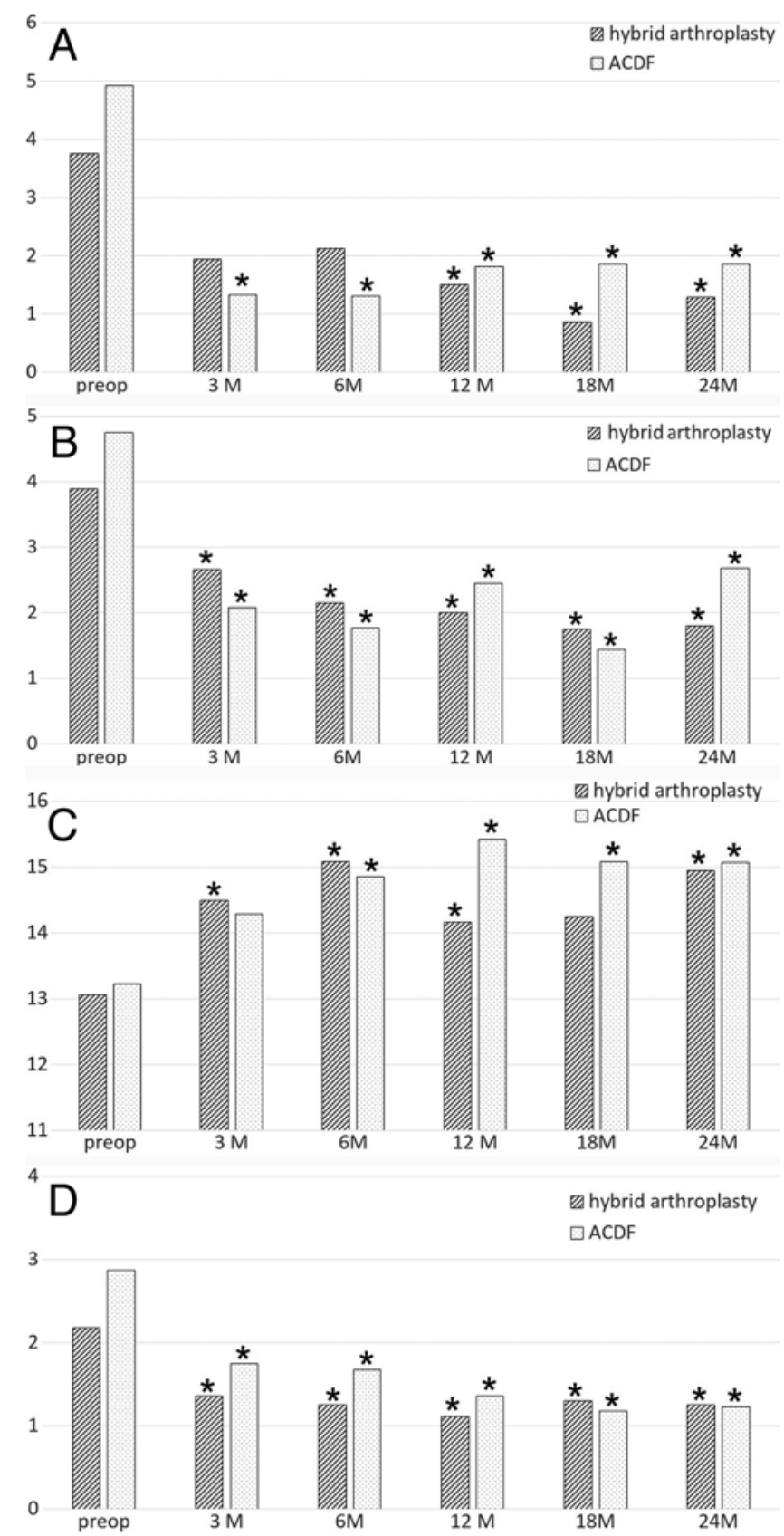

FIG. 4. Clinical outcomes for arm pain (A; VAS score), neck pain (B; VAS score), overall function (C; JOA score), and myelopathy (D; Nurick grade) at different time points of follow-up. There was no significant difference between groups. $\mathrm{M}=$ months. Asterisk = significant improvement in comparison with preoperative value.

showed a full recovery at 6-months follow-up without further sequelae. One patient in each group $(5 \%$ for the hybrid-CDA group and 5.89\% for the ACDF group; 5.41\% overall) presented with temporary hoarseness after the surgery, but the condition resolved by the first follow-up visit at 3 months postoperatively. No other complications (such as blindness, paralysis, infection, wound dehiscence, or esophageal laceration) were identified in this study. To date, no operation has been performed for symptomatic ASD (longest follow-up duration was more than 5 years), and there were no remarkable differences with respect to radiographic ASD identified in both groups at the 2-year follow-up study (CT/MRI).

\section{Discussion}

This study is the first that specifically addresses the fundamental discrepancy between CDA and ACDF in the treatment of cervical myelopathy caused by CCS, i.e., a particularly young group of patients with cervical myelopathy who should benefit more with CDA. We followed up 37 patients who met the criteria of $\leq 50$ years old, a Pavlov ratio $\leq 0.82$, and 3 -level discectomies in the subaxial cervical spine. The mean age was $44.57 \pm 5.10$ years, and the mean follow-up duration was about 2 years. After dividing these patients into the hybrid-CDA and ACDF groups, we found no significant differences in the groups' preoperative clinical parameters, and postoperatively both groups had comparable clinical improvements that presented no statistically significant differences. Radiographically, the ROM in the operated levels in both groups was also similar before the operation $\left(21.90 \pm 10.76^{\circ}\right.$ vs $21.67 \pm 6.77^{\circ}$, $\mathrm{p}=0.94)$. However, the postoperative ROM was remarkably preserved in the hybrid-CDA group $\left(10.65 \pm 5.37^{\circ}\right)$ when compared with that in the ACDF group $\left(2.19 \pm 1.17^{\circ}\right.$, $\mathrm{p}=0.0000005)$. Although both groups demonstrated excellent clinical outcomes after the surgical procedure, the study raises an interesting concern about the optimal reconstruction strategy after multilevel cervical discectomy, especially for those at younger ages.

CCS, or developmental cervical stenosis, has been previously shown to be a major risk factor for the development of CSM. ${ }^{1,25,28,35}$ There has been a lack of conclusive measurement about how to define CCS, but it has been generally agreed that the Pavlov ratio on plain radiographs-also known as SC-VB ratio or Torg-Pavlov ratio-at $\leq 0.82$ stands out as the most gratifying definition for CCS to date. After Pavlov and Torg proposed this measurement,$^{21}$ it has been widely applied in various studies about CCS and in research into sports-associated SCI among young athletes..$^{29-34}$ The advantages of this measurement, in addition to the lower cost and relatively universal availability of the radiograph, lie in the methodology with which the magnification effect produced by the variation in distance between the patient, the film, and the radiation source could be maximally reduced..$^{21} \mathrm{De}$ spite various morphological definitions having been proposed recently for CCS, ${ }^{10,12,15,18,20}$ the Pavlov ratio remains the most commonly used method in the calculation of the severity of CCS, and has been supported by previous publications. ${ }^{17,18,27,35}$

Due to the fact that CCS is attributed to an aberration in spinal cord development, ${ }^{2}$ this condition usually affects patients at younger ages in association with multilevel pathology. ${ }^{3}$ The age factor was also implemented in the inclusion criteria based on the evidence provided in the literature that higher rates of the degenerative changes occur in the sixth decade of life. ${ }^{4,16}$ The methodology of the current study was designed to weight the clinical impact contributed by CCS instead of degenerative changes.

While 1- and 2-level CDA have been proven in various 


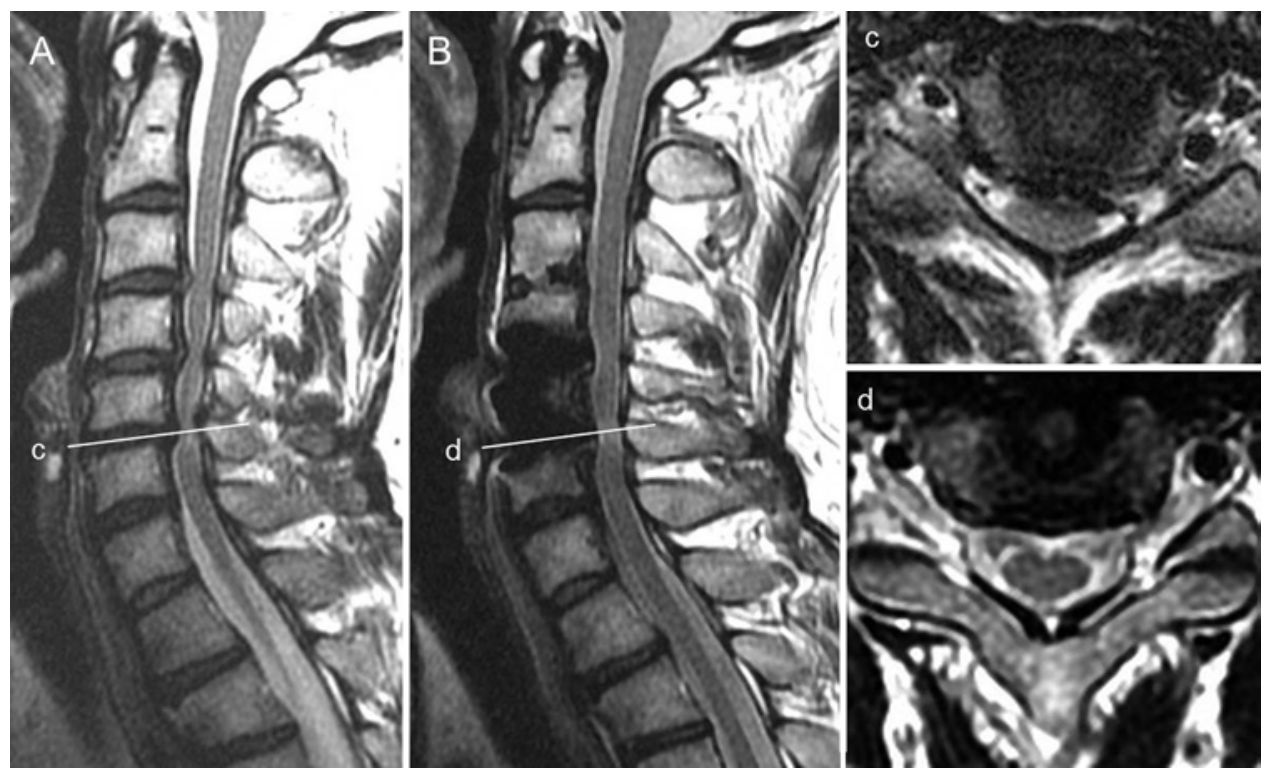

FIG. 5. Preoperative (A) and postoperative (B) MR images of 1 of the patients in the hybrid-CDA group. The axial views of the same surgical level (c and $\mathbf{d}$ ) demonstrate the degree of decompression from the surgery.

FDA-IDE trials to be safe and effective in the treatment of cervical DDDs, ${ }^{5-9,13,19,22-24,26}$ ACDF remains the gold standard surgical intervention. However, controversy exists about the optimal reconstruction strategy after anterior cervical discectomy, especially for those at younger ages. It should be noted that, despite these FDA-IDE trials including patients from 18 to 60-75 years of age, most research has presented patients with a mean age in their 40s. ${ }^{6-9,13,22-24,26}$ Yet, the essential difference between CDA and ACDF lies in the preservation of cervical motion, from which younger patients would most benefit.

Another controversy comes from the development of ASD and the attempts to avoid such an event. The presence of CCS and ASD appears to have a positive association, which is supported by a recent study by Zhang et al., in which congenital stenosis could increase the rate of radiographic ASD after initial ACDF ${ }^{36}$ Furthermore, this positive association also exists after the fusion procedure. It was noted by Eubanks et al. that, in patients who underwent 1-5-level ACDF, there was a significant association between radiographic ASD and the presence of CCS. ${ }^{11}$ From the perspective of avoiding ASD, CDA presents another biomechanical advantage of reducing the risk of ASD, which is even more heavily weighted in younger patients who have a longer life expectancy.

The limitations of this current study include the small number of patients treated in each arm, the retrospective nature of the analysis, and the nonrandomized and uncontrolled study design, even though the clinical data were prospectively collected. However, given the limited occurrence of CCS, the sample size was even markedly reduced upon strict implementation of the inclusion criteria.

Another confounding factor comes from the different arrangement of the cage and artificial discs that were implanted in the patients in the hybrid-CDA group. The arthrodesis level was sometimes designed at the cephalad and sometimes at the caudal level of the 3 levels. Despite a general principle of avoiding arthroplasty at the level of C3-4, the decision was actually made by the surgeon in charge.

The true merit of this study is that it is the first study that specifically addresses the surgical outcomes from CDA in younger patients with CCS. However, the biomechanical science of CDA as a technology with ongoing developments requires better understanding, as the implications of such technology in different clinical conditions such as CCS are even more complicated. Future studies with larger sample sizes and longer follow-up durations would be mandatory for further investigation.

\section{Conclusions}

Hybrid-CDA yielded similar clinical improvement to 3-level ACDF in patients with myelopathy caused by CCS. In this relatively young group of patients, hybrid-CDA demonstrated significantly more ROM than 3-level ACDF without ASD at 2 years' follow-up. Therefore, hybrid-CDA appears to be an acceptable option in the management of CCS. The strategy of motion preservation yielded similar improvements in cervical myelopathy compared with motion elimination (i.e., ACDF) in patients with CCS, although the theoretical benefits of reducing ASD require further validation.

\section{References}

1. Aebli N, Wicki AG, Rüegg TB, Petrou N, Eisenlohr H, Krebs $\mathrm{J}$ : The Torg-Pavlov ratio for the prediction of acute spinal cord injury after a minor trauma to the cervical spine. Spine J 13:605-612, 2013

2. Bajwa NS, Toy JO, Young EY, Ahn NU: Establishment of parameters for congenital stenosis of the cervical spine: an anatomic descriptive analysis of 1,066 cadaveric specimens. Eur Spine J 21:2467-2474, 2012 
3. Bajwa NS, Toy JO, Young EY, Ahn NU: Is congenital bony stenosis of the cervical spine associated with lumbar spine stenosis? An anatomical study of 1072 human cadaveric specimens. J Neurosurg Spine 17:24-29, 2012

4. Boden SD, McCowin PR, Davis DO, Dina TS, Mark AS, Wiesel S: Abnormal magnetic-resonance scans of the cervical spine in asymptomatic subjects. A prospective investigation. J Bone Joint Surg Am 72:1178-1184, 1990

5. Burkus JK, Traynelis VC, Haid RW Jr, Mummaneni PV: Clinical and radiographic analysis of an artificial cervical disc: 7-year follow-up from the Prestige prospective randomized controlled clinical trial: Clinical article. J Neurosurg Spine 21:516-528, 2014

6. Coric D, Kim PK, Clemente JD, Boltes MO, Nussbaum M, James S: Prospective randomized study of cervical arthroplasty and anterior cervical discectomy and fusion with long-term follow-up: results in 74 patients from a single site. J Neurosurg Spine 18:36-42, 2013

7. Coric D, Nunley PD, Guyer RD, Musante D, Carmody CN, Gordon CR, et al: Prospective, randomized, multicenter study of cervical arthroplasty: 269 patients from the KineflexIC artificial disc investigational device exemption study with a minimum 2-year follow-up: clinical article. J Neurosurg Spine 15:348-358, 2011

8. Davis RJ, Kim KD, Hisey MS, Hoffman GA, Bae HW, Gaede $\mathrm{SE}$, et al: Cervical total disc replacement with the Mobi-C cervical artificial disc compared with anterior discectomy and fusion for treatment of 2-level symptomatic degenerative disc disease: a prospective, randomized, controlled multicenter clinical trial: clinical article. J Neurosurg Spine 19:532-545, 2013

9. Davis RJ, Nunley PD, Kim KD, Hisey MS, Jackson RJ, Bae $\mathrm{HW}$, et al: Two-level total disc replacement with Mobi-C cervical artificial disc versus anterior discectomy and fusion: a prospective, randomized, controlled multicenter clinical trial with 4-year follow-up results. J Neurosurg Spine 22:15-25, 2015

10. Ellingson BM, Salamon N, Hardy AJ, Holly LT: Prediction of neurological impairment in cervical spondylotic myelopathy using a combination of diffusion MRI and proton MR spectroscopy. PLoS One 10:e0139451, 2015

11. Eubanks JD, Belding J, Schnaser E, Rowan A, Moffitt G, Weaver J, et al: Congenital stenosis and adjacent segment disease in the cervical spine. Orthopedics 36:e1251-e1255, 2013

12. Freedman BA, Hoffler CE II, Cameron BM, Rhee JM, Bawa $\mathrm{M}$, Malone DG, et al: A comparison of computed tomography measures for diagnosing cervical spinal stenosis associated with myelopathy: a case-control study. Asian Spine J 9:22-29, 2015

13. Hisey MS, Bae HW, Davis R, Gaede S, Hoffman G, Kim K, et al: Multi-center, prospective, randomized, controlled investigational device exemption clinical trial comparing Mobi-C Cervical Artificial Disc to anterior discectomy and fusion in the treatment of symptomatic degenerative disc disease in the cervical spine. Int J Spine Surg 8:7, 2014

14. Jenkins TJ, Mai HT, Burgmeier RJ, Savage JW, Patel AA, Hsu WK: The triangle model of congenital cervical stenosis. Spine (Phila Pa 1976) 41:E242-E247, 2016

15. Kang Y, Lee JW, Koh YH, Hur S, Kim SJ, Chai JW, et al: New MRI grading system for the cervical canal stenosis. AJR Am J Roentgenol 197:W134-W140, 2011

16. Lee MJ, Cassinelli EH, Riew KD: Prevalence of cervical spine stenosis. Anatomic study in cadavers. J Bone Joint Surg Am 89:376-380, 2007

17. Lozorio AR, Borges M, Batista Junior JL, Chacob Junior C, Machado IC, Rezende R: Correlation between the clinic and the index of cervical myelopathy Torg. Acta Ortop Bras 20:180-183, 2012

18. Morishita Y, Naito M, Hymanson H, Miyazaki M, Wu G,
Wang JC: The relationship between the cervical spinal canal diameter and the pathological changes in the cervical spine. Eur Spine J 18:877-883, 2009

19. Murrey D, Janssen M, Delamarter R, Goldstein J, Zigler J, Tay B, et al: Results of the prospective, randomized, controlled multicenter Food and Drug Administration investigational device exemption study of the ProDisc-C total disc replacement versus anterior discectomy and fusion for the treatment of 1-level symptomatic cervical disc disease. Spine J 9:275-286, 2009

20. Park HJ, Kim SS, Chung EC, Lee SY, Park NH, Rho MH, et al: Clinical correlation of a new practical MRI method for assessing cervical spinal canal compression. AJR Am J Roentgenol 199:W197-W201, 2012

21. Pavlov H, Torg JS, Robie B, Jahre C: Cervical spinal stenosis: determination with vertebral body ratio method. Radiology 164:771-775, 1987

22. Phillips FM, Lee JY, Geisler FH, Cappuccino A, Chaput CD, DeVine JG, et al: A prospective, randomized, controlled clinical investigation comparing PCM cervical disc arthroplasty with anterior cervical discectomy and fusion. 2-year results from the US FDA IDE clinical trial. Spine (Phila Pa 1976) 38:E907-E918, 2013

23. Sasso RC, Anderson PA, Riew KD, Heller JG: Results of cervical arthroplasty compared with anterior discectomy and fusion: four-year clinical outcomes in a prospective, randomized controlled trial. J Bone Joint Surg Am 93:1684-1692, 2011

24. Sasso RC, Smucker JD, Hacker RJ, Heller JG: Artificial disc versus fusion: a prospective, randomized study with 2-year follow-up on 99 patients. Spine (Phila Pa 1976) 32:29332942, 2007

25. Singh A, Tetreault L, Fehlings MG, Fischer DJ, Skelly AC: Risk factors for development of cervical spondylotic myelopathy: results of a systematic review. Evid Based Spine Care J 3:35-42, 2012

26. Skeppholm M, Lindgren L, Henriques T, Vavruch L, Löfgren $\mathrm{H}$, Olerud C: The Discover artificial disc replacement versus fusion in cervical radiculopathy-a randomized controlled outcome trial with 2-year follow-up. Spine J 15:1284-1294, 2015

27. Song KJ, Choi BW, Kim SJ, Kim GH, Kim YS, Song JH: The relationship between spinal stenosis and neurological outcome in traumatic cervical spine injury: an analysis using Pavlov's ratio, spinal cord area, and spinal canal area. Clin Orthop Surg 1:11-18, 2009

28. Suk KS, Kim KT, Lee JH, Lee SH, Kim JS, Kim JY: Reevaluation of the Pavlov ratio in patients with cervical myelopathy. Clin Orthop Surg 1:6-10, 2009

29. Torg JS: Cervical spinal stenosis with cord neurapraxia and transient quadriplegia. Sports Med 20:429-434, 1995

30. Torg JS: Cervical spinal stenosis with cord neurapraxia: evaluations and decisions regarding participation in athletics. Curr Sports Med Rep 1:43-46, 2002

31. Torg JS, Corcoran TA, Thibault LE, Pavlov H, Sennett BJ, Naranja RJ Jr, et al: Cervical cord neurapraxia: classification, pathomechanics, morbidity, and management guidelines. J Neurosurg 87:843-850, 1997

32. Torg JS, Naranja RJ Jr, Pavlov H, Galinat BJ, Warren R, Stine RA: The relationship of developmental narrowing of the cervical spinal canal to reversible and irreversible injury of the cervical spinal cord in football players. J Bone Joint Surg Am 78:1308-1314, 1996

33. Torg JS, Pavlov H: Cervical spinal stenosis with cord neurapraxia and transient quadriplegia. Clin Sports Med 6:115133, 1987

34. Torg JS, Ramsey-Emrhein JA: Cervical spine and brachial plexus injuries: return-to-play recommendations. Phys Sportsmed 25:61-88, 1997 
35. Yue WM, Tan SB, Tan MH, Koh DC, Tan CT: The Torg-Pavlov ratio in cervical spondylotic myelopathy: a comparative study between patients with cervical spondylotic myelopathy and a nonspondylotic, nonmyelopathic population. Spine (Phila Pa 1976) 26:1760-1764, 2001

36. Zhang JT, Cao JM, Meng FT, Shen Y: Cervical canal stenosis and adjacent segment degeneration after anterior cervical arthrodesis. Eur Spine J 24:1590-1596, 2015

\section{Disclosures}

The authors report no conflict of interest concerning the materials or methods used in this study or the findings specified in this paper.

\section{Author Contributions}

Conception and design: JC Wu, PY Chang. Acquisition of data: JC Wu, PY Chang. Analysis and interpretation of data: JC Wu, PY Chang, HK Chang. Drafting the article: JC Wu, PY Chang, HK Chang, Fay. Critically revising the article: JC Wu, PY Chang, HK Chang, Tu, CL Wu. Reviewed submitted version of manuscript: JC Wu, PY Chang, Huang, Fay, Tu, Cheng. Approved the final version of the manuscript on behalf of all authors: JC Wu. Statistical analysis: JC Wu, PY Chang, Huang, Fay, Tu, CL Wu, Cheng. Administrative/technical/material support: JC Wu, Huang, CL Wu, Cheng. Study supervision: JC Wu.

\section{Correspondence}

Jau-Ching Wu, Department of Neurosurgery, Neurological Institute, Taipei Veterans General Hospital, Rm. 525, 17F, No. 201, Shih-Pai Rd., Sec. 2, Peitou, Taipei 11217, Taiwan. email: jauching@gmail.com. 